\title{
Malignant placental trophoblastic tumour a diagnostic dilemma: rare association with focal segmental glomerulonephritis and cardiomyopathy
}

\author{
Molina U. Patel*, Chetna S. Vyas, Smruti B. Vaishnav
}

Department of Obstetrics and Gynecology, Shree Krishna hospital and HM Patel Centre for higher Education, Karamsad, Gujarat, India

Received: 20 July 2017

Accepted: 18 August 2017

*Correspondence:

Dr. Molina U. Patel,

E-mail: drmolinapatel@gmail.com

Copyright: () the author(s), publisher and licensee Medip Academy. This is an open-access article distributed under the terms of the Creative Commons Attribution Non-Commercial License, which permits unrestricted non-commercial use, distribution, and reproduction in any medium, provided the original work is properly cited.

\begin{abstract}
Placental site trophoblastic tumour (PSTT) is the rarest form of Gestational trophoblastic neoplasia (GTN).It has a wide clinical spectrum of presentation and its complications have a multi organ involvment. Inspite of the advances in HCG assays and sensitive unltrasounds, its diagnosis and course in every case is a mystery. However, it is only rarely associated with glomerulonephritis. Most cases have not been biopsied and the specific nature of renal involvement is not clearly understood. Here we report a case of PSTT with glomerulonephritis and cardiomyopathy.
\end{abstract}

Keywords: Placental site trophoblastic tumor, Glomerulonephritis (GN), Gestational trophoblastic neoplasia, Trophoblastic neoplasia

\section{INTRODUCTION}

Placental site trophoblastic tumor (PSTT) is a rare form of gestational trophoblastic disease arising from invasive intermediate gestational trophoblasts and constitutes 1 to $2 \%$ of all GTN. ${ }^{1}$ It was considered a benign lesion until Scully and Young recognized its malignant potential in $1981 .^{2}$

Due to its relatively slow lymphatic spread and chemo resistant nature, metastatic lesions to brain or kidneys often pose a diagnostic dilemma.

The association of PSTT with kidney diseases is very rare. World over, there are only a handful of cases which report its association with Lupus Nephritis, thrombotic microangiopathy (TMA) membranous glomerulonephritis. ${ }^{3}$ However, here we report one of first few cases of PSTT associated with focal segmental GN.

\section{CASE REPORT}

A 20 year old female presented with 2 months amenorrhea with complain of lower abdominal pain since 20 days. She has Full term vaginal delivery one and half year back after which she had resumed her regular menses.

UPT done was positive and USG showed changes of Vesicular Mole with multiple uterine fibroids. However, her B HCG was only 179.3 IU/L which was very low to support any intrauterine or molar pregnancy. Her pelvic examination was normal and routine lab tests showed only hypoproteinemia, Mild anaemia and mildly raised ESR. Clinically, she had minimal ascites.

Dilatation and Evacuation was done. Thereafter B HCG value was $129.6 \mathrm{IU} / \mathrm{L}$. Histopathological diagnosis revealed placental Site reaction. 
She was lost to follow up for a period of 6 months. After which she presented again with gross abdominal distension and bilateral pedal oedema with cachexia. Her B HCG was 741.1 with CA-125 of 339 and S. Albumin was 1.52 with urinary Protein of +3 . Ascitic fluid tapping and MRI showed no malignant cells.

Depending on the trend of B HCG remaining in 100's, mildly raised levels of CA-125, and MRI suggestive of uterine fibroids, differential diagnosis of PSTT, Leiomyosarcoma and Ovarian Malignancy was put, so hysterectomy was planned. Ovarian Frozen section was normal, so Total Abdominal hysterectomy was planned. Liver biopsy conducted intra operatively was normal. Histopathological finding of uterus was suggestive of Malignant PSTT.

The patients post operative course was stable till she developed DIC and heart failure with altered liver functions on the $4^{\text {th }}$ post operative day. She was admitted in intensive care unit and started on inotropes. Persistent nephrotic range of proteinuria led to her kidney biopsy, which was suggestive of Focal Segmental Glomerulonephritis. After 10 days of intensive monitoring, inotropes were tapered, she improved gradually.

Repeat investigations were towards normal side. Nephrologist opinion was done and oral steroids were started. Clinically, by $18^{\text {th }}$ Post operative day, her ascites regressed and patient was discharged on $23^{\text {rd }}$ Post operative day. She was followed up regularly with serial B HCG assays, chest X-rays and ultrasounds till 1 year. Steroids were stopped after 3 months as per nephrologist advice. Presently, she is asymptomatic and healthy.

\section{DISCUSSION}

PSTT originates from the implantation of intermediate trophoblasts.

PSTT was first described by Kurman et al as Trophoblastic Pseudo Tumor in 1976 to convey its benign nature. However, its malignant potential was first reported in 1981 by Young. In 1983, the World Health Organization (WHO) formally acknowledged its neoplastic nature and adopted the terminology PSTT. ${ }^{4}$

PSTT can occur following term labor $(63.2 \%)$, abortion $(20.6 \%)$, molar pregnancy $(15.9 \%)$ or stillbirth $(0.3 \%)$ and complicate it with multi organ involvement. ${ }^{5}$

Studies reveal that the age at presentation ranges from 20 -63 years (avg; 36 years) and the gap since the last pregnancy is on average 34 months (median of 18 months) with the mean gestity of $2 .{ }^{6}$ Each of these findings are consistent with our case.

The Aetiology and genesis of this condition is varied, as supported by studies world over. Genetic analysis showed an XX composition genomics in $89 \%$ of PSTT cases with the presence of a functional $\mathrm{X}$ chromosome of paternal origin $^{7}$.The inactivation or dysregulation of gene p53 and the up-regulation of the epidermal growth factor receptor (EGF-R) and MIB-1 also appear to play a role in the genesis of PSTT and its propagation. ${ }^{8}$

Due to unavailability of genetic studies in our case, the exact aetiology cannot be commented upon. However, immune mediated glomerular injury from DIC, may be strongly postulated in this case. Similar aetiology has been discussed by Rossen et al in his study.

Histologically, PSTTs consist in a proliferation of intermediate trophoblastic cells without chorionic villi infiltrating muscle fibers. ${ }^{9}$ They are characterized with a vascular invasion, a necrosis, and hemorrhage at a lesser extent than choriocarcinoma, and a bigger tendency to disseminate through the lymphatic track.

Clinical features such as amenorrhea, abnormal vaginal bleeding, abdominal pain and other constitutional symptoms should arouse a strong suspician. When associated with renal involvement, features of generalised edema, massive protienuria, hypoalbuminemia and ascites are seen. All these findings can be seen in our patient.

PSTT is associated with persistent low levels of serum HCG (100 - $1000 \mathrm{mIU} / \mathrm{mL})$. This is consistent with values observed in our case. However, higher serum HCG titers have been reported in patients with placental site trophoblastic tumors. ${ }^{10}$ Initial curettage is often equivocal and the diagnosis can be missed if fragments showing muscle invasion by intermediate trophoblasts are not seen.

In present case, the presence of Gross ascites, proteinuria, consistently lower levels of B-HCG, elevated CA- 125, USG findings of multiple uterine fibroids raises multiple differentials like Ovarian Malignancy, leiomyosacrcoma, Invasive Mole or any hepato renal pathology.

Urine analysis, serum creatinine concentration, albumin levels and lipid studies are few investigations that help in studying the renal involvement. Although ultrasound features like normal or enlarged kidneys with increased echogencity, shrunken kidneys with intense scarring etc may be found, histopathological evidence is definitive to stamp the diagnosis.

In present case, with histopathological confirmation of hysterectomy specimen, the malignant nature of the tumour was confirmed. The unusual renal involvement was evident in the renal biopsy report suggestive of Focal glomerulophritis with hyaline thrombi, segemental solidification of glomerular tuft with segmental accumulation of accellular matrix and obliteration of glomerular capillaries - classical for FSGN. 
The association of renal lesions and GTD is very rare. Since 1985, the precise pathological association of malignant PSTT with glomerulonephritis has been rarely reported in only a handfull of cases, as shown in Table 1.

Table 1: The reported cases of malignant PSTT with renal manifestation.

\begin{tabular}{|lllll|}
\hline Diagnosis of renal lesion & GTD & Author & $\begin{array}{l}\text { Renal biopsy } \\
\text { performed }\end{array}$ & Year \\
\hline Thrombotic microangiopathy & PSTT & Mazzucco et al $^{11}$ & Yes & 2011 \\
\hline Membranous glomerulonephritis & Invasive Mole & Yang et al $^{12}$ & Yes & 2010 \\
\hline Membranous glomerulonephritis & PSTT & Batra et al $^{13}$ & Yes & 2007 \\
\hline Membranous glomerulonephritis & Choriocarcinoma & Altiparmak et al $^{14}$ & Yes & 2003 \\
\hline Membranoproliferative glomerulonephritis & Hydatiform Mole & Komatsuda et al $^{15}$ & Yes & 1992 \\
\hline Eosinophillic deposists & PSTT & Young et al $^{16}$ & Yes & 1985 \\
\hline
\end{tabular}

Our patient is probably one of the very few cases in the country to have reported this association, none the less of the Focal Segmental variety.

The principles in the management include diagnosis, supportive therapy, proper counselling of patient as well as family and above all, timely follow -up. Non surgical management should aim to control hypertension(if any), maintaining adequate hydration, nutrition, minimizing proteinuria, preventing complications from edema and steriod use. However, Surgery remains the cornerstone of treatment. Chemotherapy should be considered for metastatic lesions and timely follow up with B HCG assays should be done.

\section{CONCLUSION}

Placental site trophoblastic tumors are exceptional tumors, encountering difficult clinical and histological diagnosis.It is a high risk obst condition requiring a multi speciality approach. Current knowledge related to PSTT is largely based on the experience of handling limited number of cases and on the experience of authors who reported small series or singular cases. Hence, more potential research is needed to guide us in resolving our diagnostic dilemma in the management of PSTT.

Funding: No funding sources

Conflict of interest: None declared

Ethical approval: The study was approved by the Institutional Ethics Committee

\section{REFERENCES}

1. Cole ME, Broaddus R, Thaker P, Landen C, Freedman RS. Placental-site trophoblastic tumors: a case of resistant pulmonary metastasis. Nature Reviews. Clin Oncol. 2008;5(3):171.

2. Piura B. Placental site trophoblastic tumor e a challenging rare entity. Eur J Gynecol Oncol. 2006;27(6):545-551.
3. Xiao C, Zhao J, Li M, Zhao D, Xiang Y. Lupus nephritis associated with placental site trophoblastic tumor: A case report and review of the literature. Gynecol Oncol Case Rep. 2014;9:26-28.

4. Huang F, Zheng W, Liang Q, Yin TDiagnosis and treatment of placental site trophoblastic tumor. Int $\mathbf{J}$ Clin Exp Pathol. 2013;6(7):1448-51.

5. Lan C, Li Y, He J, Liu J. Placental site trophoblastic tumor: lymphatic spread and possible target markers. Gynecol Oncol. 2010;116(3):430-7.

6. Feltmate CM, Genest DR, Wise L, Bernstein MR, Goldstein DP, Berkowitz RS. Placental site trophoblastic tumor: a 17-year experience at the New England Trophoblastic Disease Center. Gynecol Oncol. 2001;82:415-9.

7. Hui P, Parkash V, Perkins AS, Carcangiu ML. Patho- genesis of placental site trophoblastic tumor may require the presence of a paternally derived $\mathrm{X}$ chromosome. Lab Invest. 2000;80(6):965-972.

8. Muller-Hocker J, Obernitz N, Johannes A, Lohrs U. p53 gene product and EGF receptors are highly expressed in placental site trophoblastic tumor. Hum Pathol. 1993;28(11):1302-6.

9. Baergen RN, Rutgers JL, Young RH, Osann K, Scully RE. Placental site trophoblastic tumor: a study of 55 cases and review of the literature emphasizing factors of prognostic significance. Gynecol Oncol. 2006;100:511-520.

10. Agarwal N, Parul Kriplani A, Vijayaraghavan M. Placental site trophoblastic tumour. J Postgrad Med. 2002;48(3):211.

11. Mazzucco G, Colla L, Monga G. Kidney involvement in a patient affected by placental site trophoblastic tumor. Am J Kidney Dis. 2011;57:516520.

12. Yang JW, Choi SO, Kim BR. Nephrotic syndrome associated with invasive mole: a case report. Nephrol. Dial. Transplant. 2010;25:2023-6.

13. Batra V, Kalra OP, Mathur P. Membranous glomerulopathy associated with placental site trophoblastic tumour: a case report. Nephrol Dial Transplant. 2007;22:1766-8. 
14. Altiparmak MR, Pamuk ON, Pamuk GE. Membranous glomerulonephritis in a patient with choriocarcinoma: case report. South Med J. 2003;96:198-200.

15. Komatsuda A, Nakamoto YK. A Case report: nephrotic syndrome associated with a total hydatidiform mole. Am J Med Sci. 1992;303:309312.

16. Young RH, Scully RE, McCluskey RT. A distinctive glomerular lesion complicating placental site trophoblastic tumor: report of two cases. Hum Pathol. 1985;16:35-42.

Cite this article as: Patel MU, Vyas CS, Vaishnav SB. Malignant placental trophoblastic tumour a diagnostic dilemma: rare association with focal segmental glomerulonephritis and cardiomyopathy. Int J Reprod Contracept Obstet Gynecol 2017;6: 4711-4. 